\title{
Vulnerabilidade geológico-geomorfológica da folha Boqueirão, Paraíba
}

\author{
Geological-geomorfological vulnerability of Boqueirão sheet, Paraíba
}

Xavier $^{1}$, R. A.; Maciel ${ }^{2}$, J. S.; Silva ${ }^{3}$, V. M. A.

xavier@ceduc.uepb.edu.br

\begin{abstract}
Resumo
A Carta Geológica da Folha Boqueirão, escala 1:100.000, elaborada pelo Serviço Geológico do Brasil foi utilizada para analisar a vulnerabilidade erosiva a partir dos parâmetros geológicos e geomorfológicos. Para tanto, foi utilizado a metodologia de Creppani (2001) e Xavier et. al. (2014), para analisar a vulnerabilidade geológica e geomorfológica respectivamente. Como argumentação teórica, discutem-se os conceitos de "limites de intemperismo" e "limites de transporte" de Gilbert (1877). Os resultados mostraram a predominância da estabilidade geológica e geomorfológica da área de estudo. Rochas resistentes ao intemperismo e o relevo suave marcam a paisagem. O regime pluviométrico não favorece a atuação da pedogênese, e a ocorrência de chuvas concentradas promove a aceleração dos processos erosivos superficiais que, em alguns casos, remove todo o manto de intemperismo, formando os lajedos rochosos. Conclui-se que as ideias de Gilbert (1877) são válidas para auxiliar no entendimento da morfodinâmica em ambientes semiáridos e que as características geológicas são variáveis fundamentais neste sistema.
\end{abstract}

Palavras-chave: vulnerabilidade; geologia; Folha Keywords: vulnerability, geology; Boqueirão sheet.

\begin{abstract}
The Geological Map Sheet Boqueirão, 1: 100,000 scale, prepared by the Geological Survey of Brazil was used to analyze the erosive vulnerability from the geological and geomorphological parameters. Therefore, we used the methodology of Creppani (2001) and Xavier et. al. (2014), to analyze the geological and geomorphological vulnerability respectively. As a theoretical argument, discusses the concepts of "limits of weathering" and "transport limits" of Gilbert (1877). The results showed the predominance of the geological and geomorphological stability of the study area. Rocks resistant to weathering and flattened relief dot the landscape. The rainfall does not favor the performance of pedogenesis, and the occurrence of concentrated rainfall promotes the acceleration of surface erosion that in some cases, remove all the weathering mantle, forming the rocky floor. We conclude that Gilbert's ideas (1877) are valid to assist in the understanding of morphodynamics in semiarid environments and geological characteristics are key variables in this system.
\end{abstract} Boqueirão-PB

\section{INTRODUÇÃO}

A Carta Geológica Boqueirão, elaborada pelo CPRM (Serviço Geológico do Brasil), na escala 1:100.000, Folha SB.24-Z-D-III, abrange 15 municípios situados na microrregião do Cariri Paraibano, uma das mais secas do Brasil. Esta área apresenta importante geodiversidade, com inúmeras formações geológicas peculiares, além de grande riqueza mineral, como as maiores reservas de bentonita do país. Na área também se encontra a Área de Proteção Ambiental do Cariri e o Sítio Geomorfológico "Mar de Bolas do Lajedo do Pai Mateus", na categoria de Sítios Geomorfológicos do CPRM. Segundo Lages et. al. (2013), a região apresenta importantes sítios arqueológicos, possuindo, assim, inúmeras atrações de grande relevância para a prática do geoturismo. Desta forma, as principais atividades econômicas são, além do geoturismo incipiente e 
da mineração, práticas agropecuárias, com destaque para a criação de caprinos e agricultura em pequena escala de palma, milho, feijão, entre outros.

Do ponto de vista geomorfológico, a folha Boqueirão situa-se bem no centro da Bacia do Rio Taperoá, afluente do Rio Paraíba. Essa bacia é de grande relevância hídrica para o estado da Paraíba, pois alimenta o açude de Boqueirão, que é o responsável por abastecer as principais cidades do Cariri, incluindo Campina Grande. Nos últimos anos diversos estudos têm apontado para um aumento da degradação ambiental em geral, e do processo de desertificação em particular (Souza, 2008; Souza et. al., 2004 e 2009; Seabra, et. al., 2014 e 2015). Essa degradação tem na erosão dos solos uma de suas principais características, o que de certa forma é preocupante a medida que o assoreamento dos cursos d’água e, principalmente, do açude de Boqueirão, comprometerá a sustentabilidade hídrica e, por conseguinte, socioeconômica da região.

Assim, o presente trabalho tem como objetivo fazer uma análise da vulnerabilidade à erosão considerando os aspectos geológicos e geomorfológicos da Folha Boqueirão, e discutir os princípios morfodinâmicos a luz da teoria dos "limites de intemperismo" e "limites de transporte" de Gilbert (1877).

\section{LIMITES DE INTEMPERISMO E LIMITES DE TRANSPORTE}

Para Gilbert (1877), a esculturação da paisagem é governada por processos naturais que ocasionam a fragmentação e remoção dos materiais. A esse conjunto de processos Gilbert denominou de erosão. A erosão para ele consistiria de duas etapas fundamentais: a primeira seria a desintegração das rochas; e a segunda, o transporte dos materiais desintegrados. A primeira etapa da erosão - desintegração das rochas - seria desenvolvida por outros dois processos: o intemperismo e a corrasão. As rochas existentes na crosta terrestre são desintegradas pelo intemperismo disponibilizando materiais fragmentados para serem transportados por canais de drenagem para os oceanos e outros reservatórios terminais. Para Turkington et. al. (2005) o intemperismo é indiscutivelmente o mais crucial e fundamental fenômeno na evolução da paisagem e no desenvolvimento topográfico.

Contudo, Gilbert op cit, ressaltou que os processos que conduzem a esculturação da superfície da Terra não atuam isoladamente, ao contrário, estão interligados e alimentam-se dessa relação. Dessa forma, os processos de intemperismo são influenciados pelos processos de transporte, aos quais estão diretamente associados à declividade das encostas. Quando as taxas de transporte forem maior que as taxas de intemperismo, podendo até atingir a remoção completa dos materiais intemperizados, o perfil de intemperismo seria pouco espesso, pois essa condição não 
favoreceria a estocagem de água e, dessa forma, esta teria pouco tempo de contato com a rocha para provocar reações químicas.

Stallard (1988), influenciado pelas ideias de Gilbert, mencionou que os processos de movimentos de massa residem entre os limites de intemperismo e os limites de transporte. Quando a capacidade de transporte excede a taxa em que o intemperismo produz materiais, até remover completamente os materiais, expondo a rocha. Nesse caso, formar-se-iam os lajedos, que seriam extensas superfícies rochosas, em sua maioria graníticas, tão comuns no semiárido.

Os princípios Gilbertianos são compatíveis com os conceitos de morfogênese e pedogênese na morfodinâmica da paisagem. Com efeito, a morfodinâmica da paisagem geomorfológica, ou seja, sua evolução morfológica no tempo e no espaço, seria governada pelos processos morfogenéticos e pedogenéticos. Assim, a superfície topográfica evoluiria, de forma mais efetiva, com um certo sincronismo entre as taxas de intemperismo e de erosão dos solos. Nesse caso, o tipo de rocha e sua resistência ao intemperismo, e a condições climáticas de temperatura e umidade definindo a intensidade do intemperismo, são variáveis fundamentais ao entendimento da evolução de uma determinada paisagem geomorfológica.

\section{METODOLOGIA}

A área de estudo compreende os limites da Folha SB.24-Z-D-III Boqueirão, que abrange 15 municípios total ou parcialmente, são eles: Campina Grande, Pocinhos, Puxinanã, Olivedos, Soledade, Juazeirinho, Gurjão, Boa Vista, São João do Cariri, Cabaceiras, São Domingos do Cariri, Boqueirão, Barra de Santana, Caturité e Queimadas (Figura 1).

A vulnerabilidade à erosão dos solos, a partir da análise das características geológico e geomorfológica, foi obtida aplicando-se os princípios de morfogênese e pedogênese que permearam a metodologia de vulnerabilidade proposta por Crepanni et. al., 2001.

A metodologia proposta por Crepanni et al. (2001) é fundamentada na caracterização morfodinâmica das unidades de paisagem resultantes da relação entre os processos de morfogênese e pedogênese embasada nos princípios da Ecodinâmica de Tricart (1977). Tricart (1977) estabeleceu três categorias morfodinâmicas: - Meios estáveis: caracterizados pela cobertura vegetal densa, dissecação moderada e ausência de manifestações vulcânicas, com favorecimento à pedogênese; - Meios intergrades: caracterizados pelo balanço entre as interferências morfogenéticas e pedogenéticas e pela transição entre os meios estáveis e instáveis; - Meios fortemente instáveis: condições bioclimáticas agressivas com variações fortes e irregulares de ventos e chuvas, relevo 
com vigorosa dissecação, presença de solos rasos, baixa densidade de cobertura vegetal, planícies e fundos de vale sujeitos a inundações e geodinâmica interna intensa. Nesse sentido, as unidades de paisagem resultantes desta integração de fatores naturais que apresentam maior estabilidade e predomínio da pedogênese são representadas por valores de vulnerabilidade próximos de 1,0; as unidades de estabilidade intermediária são representadas por valores próximos de 2,0, e as unidades territoriais básicas mais vulneráveis, com predomínio dos processos de morfogênese, apresentam valores próximos de 3,0 (CREPANI et al., 2004). As unidades de paisagens classificadas como estáveis, intermediárias ou fortemente estáveis e as vulnerabilidades de seus solos são resultantes do balanço entre os processos morfogenéticos e pedogenéticos. Crepani et al (2001) ressalta que todas as informações são fornecidas pela geologia, geomorfologia, pedologia, fitogeografia e climatologia, e sua integração fornece um retrato fiel do comportamento de cada unidade frente à sua ocupação (CREPANI et al., 1996). Neste estudo, apenas as variáveis geologia e geomorfologia serão trabalhados a fim de comparar e discutir à luz da teoria dos "limites de intemperismo" e "limites de transporte" de Gilbert (1877).

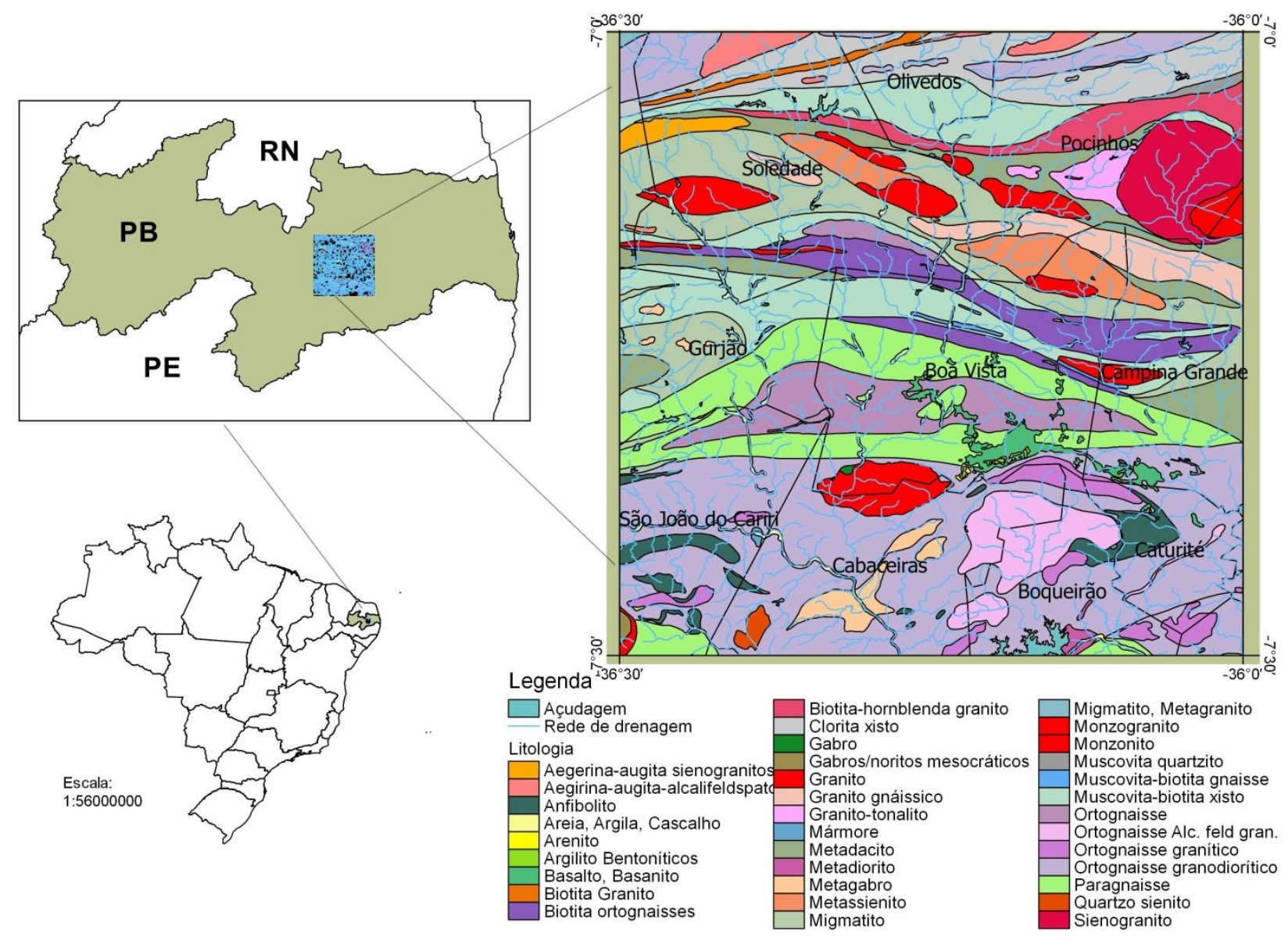

Figura 1. Geologia da Folha Boqueirão 1:100.000, CPRM, 2012. 
Para a classificação do relevo da Folha Boqueirão, foram considerados como descritores a amplitude do relevo e a declividade, seguindo o método proposto por Xavier et. al., 2014.

As classes e parâmetros utilizados em suas definições podem ser observados a seguir:

1. Superfícies Aplainadas - amplitude menor que 60 metros e declividade inferior a $3^{\circ}$

2. Superfícies suavemente onduladas - amplitude menor que $100 \mathrm{~m}$ e declividade maior que $3^{\circ}$ e menor que $12^{\circ}$.

3. Colinas Suaves - amplitude entre 100 e $300 \mathrm{~m}$ e declividade menor que $5^{\circ}$.

4. Colinas Onduladas -amplitude entre 100 e $300 \mathrm{~m}$ e declividade entre 5 e $25^{\circ}$.

5. Serras Elevadas - amplitude maior que 300m

\section{RESULTADOS E DISCUSSÃO}

A geologia da Folha Boqueirão é marcada por rochas cristalinas, compostas em sua maioria por rochas metamórficas, como os ortognaisses, migmatitos, anfibolitos, serpentinitos, paragnaisses, micaxistos, quartzitos, mármore, entre outros (CPRM, 2012). As rochas ígneas vêm em seguida, sendo mais comuns as plutônicas (granitos) e uma pequena ocorrência de rochas vulcânicas (basaltos), no município de Boa Vista. As rochas sedimentares são pouco expressivas na geologia da carta, sendo restrita aos leitos fluviais ocupados por depósitos aluvionares, e uma pequena área de ocorrência de arenito, no município de Boa Vista (Figura 1).

A vulnerabilidade geológica apresenta-se baixa na área estudada. A forte presença de rochas cristalinas muito resistentes aos processos de intemperismo,conferem a área certa estabilidade morfodinâmica na paisagem gemorfológica. Os resultados da vulnerabilidade geológica mostraram que a Folha Boqueirão é estável quanto aos processos de intemperismo, ocupando 78,3\% da área da folha (Figura 2 e Tabela 1). Somando-se a categoria moderadamente estável, que ocorreu em 10,7\% da área, chega-se a $89 \%$ da área total da folha. Essa condição de estabilidade dinâmica da geologia confere condições para a atuação da pedogênese, contudo, as condições climáticas de baixa umidade não favorecem as transformações causadas pelo intemperismo. 


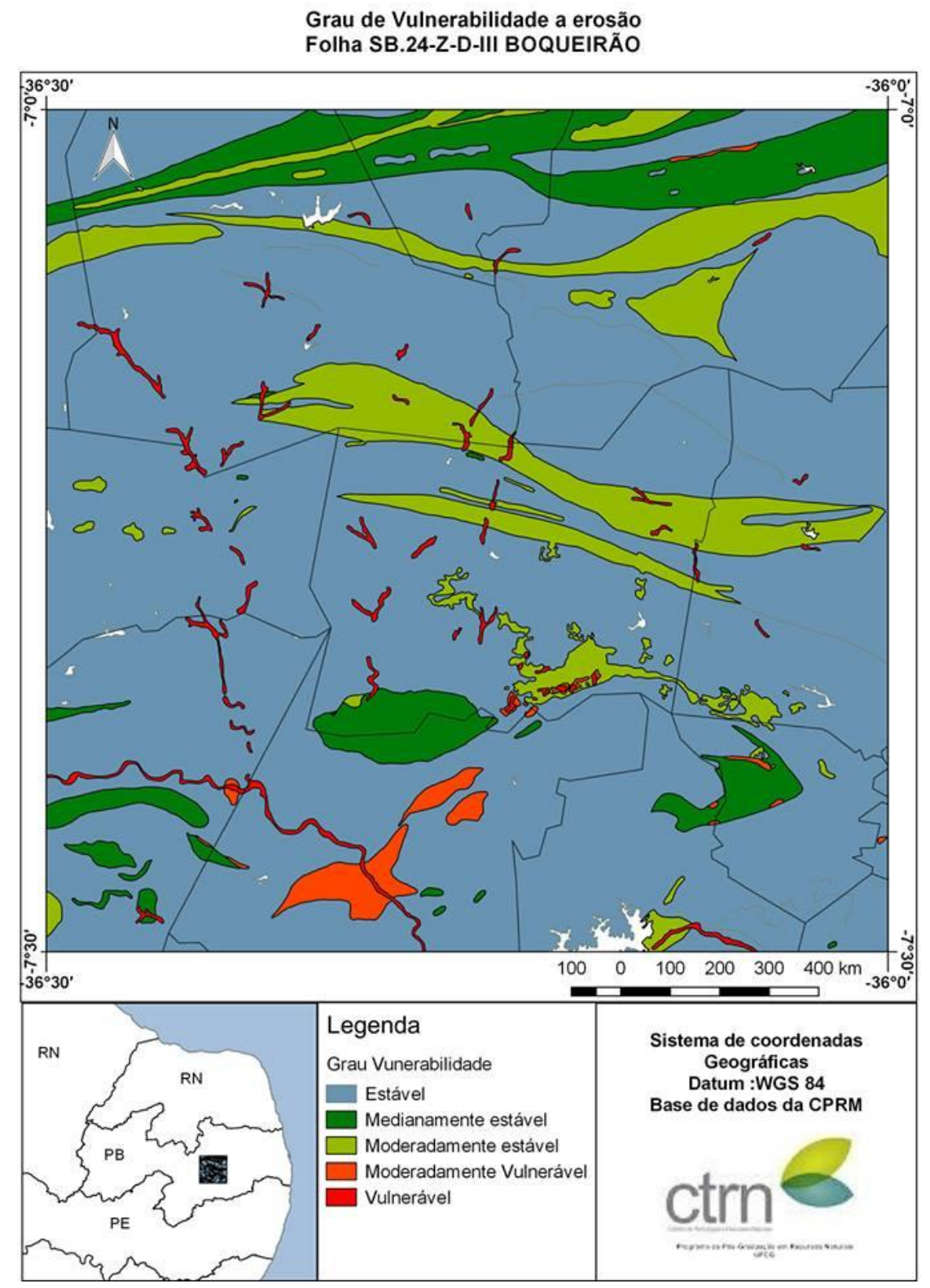

Figura 2. Mapa de vulnerabilidade geológica da Folha Boqueirão-PB.

Tabela 1. Grau de vulnerabilidade geológica para a Folha Boqueirão-PB.

\begin{tabular}{lll}
\hline Grau de vulnerabilidade & Área total $(\mathrm{km} 2)$ & $\%$ da área \\
\hline Vulnerável & 31,52 & 1,0 \\
Moderadamente vulnerável & 36,43 & 1,2 \\
Medianamente estável/vulnerável & 266,95 & 8,8 \\
Moderadamente estável & 325,84 & 10,7 \\
Estável & 2383,32 & 78,3 \\
Total & 3044,06 & 100 \\
\hline
\end{tabular}


A Folha Boqueirão está inserida na unidade geomorfológica do Planalto da Borborema. Assim, concordamos com Corrêa et. al. (2010) ao definirem o Planalto da Borborema como:

(...) conjunto de terras altas contínuas que se distribuem ao longo da fachada do Nordeste oriental do Brasil, ao norte do rio São Francisco, acima da cota de 200 metros, cujos limites são marcados por uma série de desnivelamentos topográficos, cuja gênese epirogênica está ligada ao desmantelamento do Gondwana e ao magmatismo intraplaca atuante ao longo do Cenozóico. (CORRÊA et. al., 2010, p.35)

O mapeamento geomorfológico da Folha Boqueirão confirmou a estabilidade geológica observada anteriormente. A unidade que mais se destaca na paisagem é a de superfícies suavemente onduladas, representando cerca de $70 \%$ da área total (Tabela 2). Em seguida prevalecem as superfícies aplainadas ocupando 15,5\% da área. Somando-se as duas unidades, observa-se que o relevo predominante é bastante desgastado marcando uma extensa superfície de baixa declividade (Figura 3). Essa vasta superfície é interrompida pontualmente por colinas, que em alguns casos são lajedos, e raramente por serras elevadas, geralmente associada as rochas graníticas. Essa característica é típica da região semiárida nordestina, pois de acordo com Mabessone (1978, p. 5), nos sertões semiáridos do Nordeste brasileiro, "o elemento mais conspícuo dentro das formas do relevo é a extensão enorme das áreas planas ou quase planas”.

Tabela 2. Compartimentação geomorfológica da Folha Boqueirão-PB

\begin{tabular}{lcc}
\hline Unidade & Área total $(\mathrm{km} 2)$ & $\%$ da área \\
\hline Superfícies aplainadas & 460,3 & 15,5 \\
Superfícies suavemente onduladas & 2069,5 & 69,7 \\
Colinas suaves & 319,3 & 10,7 \\
Colinas onduladas & 118,6 & 4,0 \\
Serras elevadas & 2,71 & 0,1 \\
Total & 2970 & 100 \\
\hline
\end{tabular}

Apesar da relativa estabilidade geológico-geomorfológica, a morfodinâmica não é marcada pela pedogênese, uma vez que o clima semiárido com baixos índices de pluviosidade (Tabela 3) não propicia a alteração das rochas pelos processos de intemperismo. Ao contrário, o regime de chuvas concentradas em três meses potencializa a ocorrência de chuvas torrenciais, e a geração de escoamento superficial nas encostas, fazendo com que a morfogênese seja predominante. Em muitos setores o limite de intemperismo é atingido quando a morfogênese, ou seja, a erosão superficial neste caso remove todo o material de alteração, expondo vastas áreas rochosas, conhecidas como lajedos. Na Folha Boqueirão, destaca-se na paisagem o Lajedo Pai Mateus, que segundo Lages et. al. (2013). 
..."compreende um grande pavimento rochoso de forma dômica assimétrica do tipo waleback (por lembrar o dorso de uma baleia) cujo eixo maior tem mais de $1 \mathrm{~km}$ de extensão. A diferença de cota em relação à base de sua planície de pediplanação pode chegar a 100m. Sobre este grande lajedo, dispõe-se cerca de uma centena de imensos blocos e matacões esfoliados com diferentes graus de arredondamento e formas, caracterizando um "Mar de Bolas" no coração do Sertão do Cariri Paraibano." (Lages et. al., 2013, p. 5)

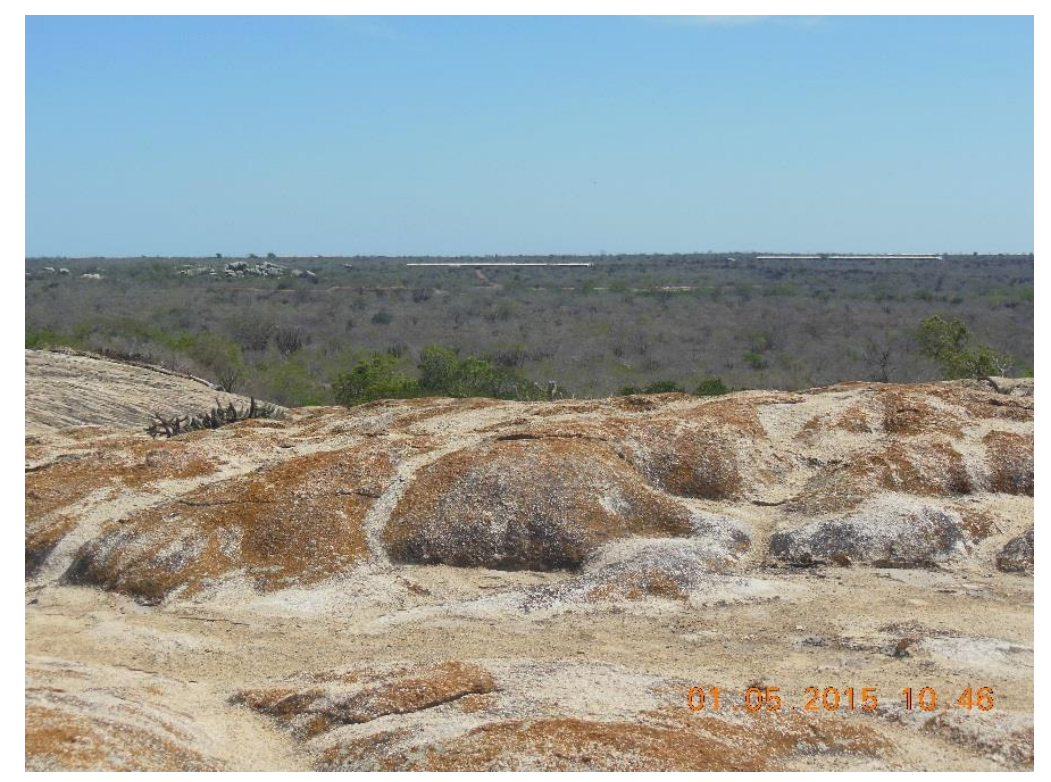

Figura 3. Em primeiro plano parte da superfície rochosa do Lajedo do Bravo, no município de Boa Vista-PB, e ao fundo a extensa superfície aplainada.

Tabela 3. Precipitação anual média para alguns municípios integrantes da Folha Boqueirão-PB.

\begin{tabular}{lccc}
\hline Município & $\begin{array}{c}\text { Precipitação média } \\
\text { anual }(\mathrm{mm})\end{array}$ & Desvio padrão (mm) & Série de dados (anos) \\
\hline Boa Vista & 418,8 & 165,2 & 47 \\
Boqueirão & 534,0 & 164,1 & 20 \\
Cabaceiras & 316,6 & 187,1 & 65 \\
Campina Grande & 765,5 & 202,7 & 72 \\
Gurjão & 473,8 & 179,9 & 23 \\
Juazeirinho & 510,4 & 235,9 & 24 \\
Olivedos & 485,3 & 228,7 & 53 \\
Pocinhos & 386,0 & 163,8 & 63 \\
Queimadas & 410,9 & 222,7 & 55 \\
São João do Cariri & 384,8 & 178,2 & 52 \\
Soledade & 400,9 & 183,5 & 77 \\
Média & 462,4 & 118,91 & - \\
\hline
\end{tabular}

Fonte: Departamento de Ciências Atmosféricas, Universidade Federal de Campina Grande-PB, 2016.

\section{CONSIDERAÇÕES FINAIS}

A Carta Geológica da Folha Boqueirão apresenta grau de vulnerabilidade estável a moderadamente estável na maior parte da área. Associado a compartimentação geomorfológica, 
constatou-se que a paisagem é marcada por superfícies aplainadas e muito resistente aos processos de intemperismo. Em condições favoráveis de umidade, os processos pedogenéticos prevaleceriam sobre os morfogenéticos. Contudo, os baixos índices pluviométricos relacionados as rochas resistentes ao intemperismo, como os granitos, tornam o ambiente propício a formação dos lajedos através da remoção total dos mantos de intemperismo. Por fim, as ideias de Gilbert (1877) sobre os "limites de intemperismo" e os "limites de transporte", bem como os conceitos de morfogênese e pedogênese, são úteis ao entendimento da evolução geomorfológica no semiárido paraibano.

\section{REFERÊNCIAS}

CORREA, A.C.de B., TAVARES, B. de A. C., MONTEIRO, K. de A., CAVAlCANTI, L. C. de S. e LIRA, D. R. de. Megageomorfologia e morfoestrutura do planalto da Borborema. Revista do Instituto Geológico, São Paulo, 31 (1/2), 35-52, 2010.

CPRM - SERVIÇO GEOLÓGICO DO BRASIL. Carta geológica folha SB.24-Z-D-III Boqueirão. Escala 1:100.000, 2012.

CREPANI, E.; MEDEIROS, J. S. de; HERNANDEZ Fº, P. FlORENZANO, T. G.; DUARTE, V.; e BARBOSA, C. C. F. Sensoriamento remoto e geoprocessamento aplicados ao zoneamento ecológico - econômico e ao ordenamento territorial. Ministério da Ciência e Tecnologia Instituto Nacional de Pesquisas Espaciais. Apostila (INPE-8454-RPQ/722). São José dos Campos SP, 2001. CREPANI, Edison et.al. Curso de Sensoriamento Remoto aplicado ao Zoneamento EcológicoEconômico. Metodologia desenvolvida para subsidiar o Zoneamento Ecológico-Econômico e capacitar os técnicos dos Estados da Amazônia Legal. São José dos Campos: INPE, 1996.

CREPANI, E.; MEDEIROS, J. S.; PALMEIRA, A. F. Intensidade pluviométrica: uma maneira de tratar dados pluviométricos para análise da vulnerabilidade de paisagens à perda de solo. São José dos Campos: Instituto Nacional de Pesquisas Espaciais, 2004.

CREPANI, E. et al. Sensoriamento Remoto e Geoprocessamento aplicados ao Zoneamento Ecológico Econômico e ao ordenamento territorial. São José dos Campos: Instituto Nacional de Pesquisas Espaciais, 2001.

GILBERT, G. K. 1877. Report on the geology of Henry mountains. U.S. Geog. \& Geol. Survey of the Rocky Mountain Region. Department of the Interior. Washington. 151p.

LAGES, G. de A.; MARINHO, M. de S.; NASCIMENTO, M. A. L. do; MEDEIROS, V. C. de; DANTAS, E. L. \& FIALHO, D. Mar de Bolas do Lajedo do Pai Mateus, Cabaceiras, PB: Campo de matacões graníticos gigantes e registros rupestres de civilização pré-colombiana. Sítios Geológicos e Paleontológicos do Brasil. In: Winge,M.; Schobbenhaus,C.; Souza,C.R.G.; Fernandes,A.C.S.; 
Berbert-Born,M.; Sallun filho,W.; Queiroz,E.T.; (Edit.) Sítios Geológicos e Paleontológicos do Brasil, 2013.

MABESSONE, J. M. Panorama geomorfológico do Nordeste brasileiro. Geomorfologia, n.56, 1978. p.1-16.

SEABRA, V. S., XAVIER, R. A.; DAMASCENO, J.; DORNELlAS, P. C. Mapeamento do Uso e Cobertura do Solo da Bacia do Rio Taperoá: Região Semiárida do Estado da Paraíba. Revista Caminhos de Geografia, Uberlândia. V.15, n.50, p. 127-137. ISSN 1678-6343. 2014.

SEABRA, V. S., XAVIER, R. A.; DAMASCENO, J.; DORNELLAS, P. C. Análise das mudanças de uso e cobertura da terra na bacia do rio Taperoá-PB entre os anos de 1990 e 2009. Anais XVII Simpósio Brasileiro de Sensoriamento Remoto - SBSR, João Pessoa-PB, INPE, Brasil, 2015.

SOUZA, B. I.; SILANS, A.M.B.P.; SANTOS, J.B. Contribuição ao estudo da desertificação na Bacia do Taperoá. Revista Brasileira de Engenharia Agrícola e Ambiental, v.8, n.2-3, 2004.

SOUZA, B. I. de. Cariri Paraibano: do silêncio do lugar à desertificação. Porto Alegre: UFRGS/PPGEO, tese de doutorado, 2008.

SOUZA, B.I., SUERTEGARAY, D.M.A. e LIMA, E.R.V. Desertificação e seus efeitos na vegetação e solos do Cariri Paraibano. Mercator - Revista de Geografia da UFC, ano 08, número $16,2009,217-232$.

STALLARD, R. F.. Weathering and erosion in the humid tropics. In: Physical and chemical weathering in geochemical cycles. Editores: Lerman, A. E Meybeck, M. NATO ASI Series. Kluwer Academic Publishers, 1988, 225-246pp.

TRICART, J. - Ecodinâmica. Rio de Janeiro: IBGE/SUPREN, 91p, 1977.

TURKIngton, A. V., Phillips, J. D., Campbell, S. W.. Weathering and landscape evolution. Geomorphology 67, 2005,1-6.

XAVIER, R.A., SEABRA, V. DA S., DAMASCENO, J. \& DORNELLAS, P. DA C.. Mapeamento de unidades geomorfológicas na bacia do rio Taperoá, região semiárida da paraíba, utilizando modelo digital de elevação (MDE) Topodata. REVISTA GEONORTE, Edição Especial 4, V.10, N.3, p.166-171, 2014

\section{AGRADECIMENTOS}

Os autores são gratos ao CNPq, a UFCG e a UEPB por apoiarem o desenvolvimento desta pesquisa.

Recebido em: 14/08/2016

Aceito para publicação em: 01/10/2016 